III.-On the Structure of the Valves of Eupodiscus Argus and Isthmia enervis, showing that their silicious deposit conforms to the general plan of deposition in simpler forms. By Henry J. Slack, F.G.S., Sec. R.M.S.

(Read before the Royai, Micnoscorical Society, Nov. 6, 1872.)

Plate XL. (Middle portion).

THE observations now brought before the Royal Microscopical Society may be regarded as a continuation of those previously communicated on Pinnularia, as they have the same object, and tend towards the same conclusion that the silicious deposition in diatoms probably follows one uniform plan, and that the silex is deposited in spherules, varying in dimensions and in degree of proximity; thus according with Mr. Wenham's researches.

Since the publication of the paper on Pinnulariæ numerous fresh observations have been made, confirming the results then mentioned, and efforts were occasionally directed towards elucidating the structure of such forms as Isthmia enervis and Eupodiscus Argus, and showing their agreement with the ordinary types; but without satisfactory results so long as only old means were employed.

Lately, with the help of Mr. Wenham's "Improved Reflex Illuminator," described in a paper read before this Society last May, and published in the June number of this Journal, the markings of Eupodiscus Argus have been so clearly displayed as to leave little doubt of the real structure, and those of Isthmia enervis have been exhibited so as to indicate that the aberrant character shown under ordinary illumination is the result of a peculiar arrangement of minute beads viewed under circumstances of optical confusion.

No thoughtful microscopist could be satisfied with the views Eupodiscus Argus obtained by ordinary means, and corresponding in general effect with the figure given in the "Micrographic Dictionary,' pl. 12. In Smith's work on the Diatomacere a better figure was given, but far from being right, though at the time of its publication there was probably no particular reason known for doubting its correctness.

The figures in the 'Micrographic Dictionary' (2nd edition) would suggest to anyone familiar with the confusion arising from defective illumination and the superposition of transparent surfaces that it must be wrong. It represents a number of bright objects something like white stars with short rays, on a dark ground of general confusion. In the text of the same work the genus Eupodiscus is described as having valves that "appear either distinctly areolar, the depressions being large: granular from their 
being minute; or striated." In the last edition of "Pritchard's Infusoria 'we are told that Eupodiscus Argus is "easily recognized by its irregular cellulns and intervening puncta, which give the disk a clouded appearance very unlike the usual transparency of Diatomacer."

Until Mr. Wenham's researches settled the old disputes $†$ as to whether the markings on ordinary diatoms were elevations or depressions such phraseology as the above might be admissible, but careful examination of the objects with the best optical means now at the command of the microscopist may be expected to banish such terms as " areolar," "cellules," \&c., from the descriptions of diatoms; the so-called "cellules" being spherules of silica, and the "areolæ" (little spaces) — not at all corresponding with what is generally meant by such a term.

At the end of Mr. Wenham's paper on the new illuminator, he remarks that " in English-mounted slides of diatoms and insect scales, some are always found detached from the cover and on the slide, and are shown well with it; but such is not the case with Möller's and others: they raise their covers off the slides by a ring of cement, and in many of them, I have searched in vain for a solitary specimen that has become detached." In my specimen of Möller's type slide some diatoms were found that could be well exhibited by Mr. Wenham's plan, though not by the same action of his instrument as when dry slides are used. Among these were the Eupodisci placed at the corners of each series. This result was not, however, arrived at without a good deal of trouble and practice in using the apparatus, and microscopists who take it up for the first time must not be disappointed if they frequently fail in its employment until they have spent a good many evenings in testing its action at various points of rotation, with the sub-stage mirror throwing up the light, and at various angles.

When successfully employed upon Eupodiscus Argus a considerable portion of the circular valve will become clear and plain, and it will be seen that it is entirely composed of spherules of different sizes and varied aggregation. Radiating from a central portion, occupied by minute and closely-packed spherules, bands will be seen proceeding to the circumference, each one composed of minute spherules that appear in close contact under an $\frac{1}{8}$, with eye-pieces up to D of Ross' system. Between these bands are larger spherules, frequently, but by no means universally, arranged in fours, so that when seen with powers too low for their distinct separation they

* In the edition of the 'Mic. Dic.' now issuing in numbers, pl. 12, an additional figure is given of part of a valve of $L$. Arg's a little nearer the mark, but far from being right.

$\dagger$ This was written, not anticipating Mr. Stewart's remarks in discussing this paper. The exact refractive power of various diatoms - for they seem to differshould be ascertained. 
appear to form patterns like the Gothic quatrefoils, and look like holes when the light passes straight through them.

To see this structure well the mirror must be inclined so that the light given by Mr. Wenham's apparatus all passes a little askew through the spherules. When, through refraction or reflexion, any light passes straight, or nearly straight, through the larger spherules, they look like holes through which a glare penetrates, and all minutiæ of structure disappear. A slight change in the angle of the mirror, or of the position of the Wenham illuminator effected by partial rotation, will leave the larger spherules in a quiet glow, as if they were incompletely transparent, while the smaller spherules of the radial bands glisten a pearly lustre. A $\frac{1}{5}$ th of Beck's with a deep eye-piece is sufficient to show this structure, but an $\frac{1}{8}$ th will do it better, and an excellent effect was obtained with Powell and Lealand's new pattern and dry front.

Good specimens of Eupodiscus Argus should be examined as uncovered objects both with Mr. Wenham's apparatus and with that devised for opaque objects under high powers by Professor Smith. The writer has hitherto had no opportunity of trying these plans.

With regard to Isthmia enervis, the 'Micrographic Dictionary' describes the valves as "without linear thickenings, uniformly covered with depressions," and the valves of the genus generally are spoken of as having "depressions so large as to produce a distinct reticular or cellular appearance when viewed by ordinary illumination." This last remark is quite correct, and the "distinctness" of the appearance has caused it to pass unquestioned.

In a last edition of 'Pritchard's Infusoria' the valves of Isthmia enervis are described as having "large, somewhat quadrate cellules," which corresponds with the appearances ordinarily seen. In the same work, at page 42, is a quotation from 'Silliman's Journal,' describing experiments of Professor Bailey, who viewed diatom valves with the microscope while they were being acted on with dilute hydrofluoric acid. "In Isthmia," he said, "the spots on the surface which appear like granular projections, are in reality thin portions of the shell, and under the action of the acid they soon become holes." It is obvious that the parts which dissolve first must either be the thinnest or so constructed as to present the greatest surface to the acid. Professor Bailey's observations must therefore guide us in deciding which of several appearances the valves can be made to assume under high powers and various modes of illumination.

The writer has not yet been fortunate enough to find specimens of Isthmia so situated as to show in the best manner with Mr. Wenham's illuminator, but with a fine $\frac{1}{8}$ th objective and that apparatus the simple cellular or reticulated appearance disappears, and great numbers of minute spherules at different levels can be 
discerned; and its structure is thus seen to conform to ordinary types.

In Plate XL., a portion of the valve of Eupodiscus Argus is shown as seen in the manner described. No figure of Isthmia is given, because, though enough was seen to justify the preceding remarks, some important points in the arrangement of the minute spherules were left in doubt.

\section{IV.-Notes on the Development of the Nervous System of the} Annulosa. By B. T. Lowne, M.R.C.S., F.L.S., Lecturer on Physiology at Middlesex Hospital Medical School.

(licul bufore the Royal Microscopical Society, Nov. 6, 1872.)

Piate XL. (Lower portion).

A YEAR and a half ago (January 11, 1871) I had the honour of reading a paper before you "On the Anatomy of Ascaris lumbricoides," and I then ventured to express the opinion that the nervous system of the Invertebrata is developed, like that of the Vertebrata, from the serous layer of the blastoderm. I had at that time set myself the task of working out the subject, but time has not sufficed to do what I had wished, and as a year or more may yet elapse before I have worked out this interesting matter, I have been induced to give you a résumé of what is at present known on this head, and to furnish you with the principal facts which have led me to believe that such is really the case.

In June, 1871, Dr. E. Metschnikoff published an essay in Kölliker's 'Zeitschrift' on the development of scorpions, which has confirmed my opinion, as his observations are a connecting link between my own as yet imperfect researches. This essay changed what was little more than suspicion in my mind into a strong belief.

\section{DESCRIPTION OF PLATE XL. (Lower portion).}

FIG. 1.-The ventral surface of an embryonic scorpion, showing the chaiu of ganglia, $a$, on either side of the primitive furrow, one being situsted at the base of each appendage. After Metschnikoff.

2.--A transverse section through one of the ganglia and lateral appendages of a younger embryo. $a$, ganglion in the epiblast; $b$, rudiment of a leg outside the ganglion; $\boldsymbol{c}$, mesoblast ; $d$, hypoblast. After Metschnikoff.

"3.-The extremity of the abdomen of a scorpion embryo, showing the splitting of the mesoblast to form the body cavity. $a^{\prime}$, epiblast; $c$, mesoblast; $d$, hypoblast ; $e$, body cavity. After Metschuikoff.

, 4.-A section of the entothoracic epiphysis of the mesothorax of a fly, showing its relation to the nerve ganglia. $a$, process of integument; $b$, nerve centre bound down to the thorax; c, nerves passing from it. 